\title{
Review of Research on In-vehicle Pollutants in China
}

\author{
Ming $\mathrm{LI}^{1,2, *}$, \\ ${ }^{1}$ State Key Laboratory of Automobile Dynamic Simulation, \\ ${ }^{2}$ Department of Thermal Energy Engineering, \\ Jilin University, Changchun, Jilin province 130022, China \\ e-mail: limingtiger@jlu.edu.cn \\ Chang-hua WEI \\ Jiangsu chaoli-electric Co. Ltd. Dangyang, \\ Jiangsu province, 212300, China
}

\begin{abstract}
With the improvement of living standard, vehicles have been widely used in life. However, health problems associated with in-vehicle air quality happen more frequently. Recent researches on in-vehicle air quality control measures for human health are reviewed in this paper. The problems and challenges in the existing researches are summarized accordingly. Further study is suggested on air quality control for healthy in-vehicle air environment.
\end{abstract}

Keywords-In-vehicle air quality; air pollution; human health

\section{INTRODUCTION}

Automobile has been used in our life world widely. One of the purposes of vehicle is to provide convenient and save time for drivers. With the improvement of standard of living, drivers require more and more comfortable and healthful environment in the cab. The factors affecting in-vehicle air quality mainly include temperature, humidity, air exchange rate, air movement, ventilation, particle pollutants, biological pollutants, and gaseous pollutants (Peng Liang, etc. 2012). Many researchers have widely investigated the composition of in-vehicle pollutants, sources, physical and chemical characteristics, and effects on human health.(Yaosheng He,2014) . By analyzing recent studies, in-vehicle environment problems could affect drivers' health. Therefore in-vehicle air pollution attracts more and more people to pay attention to solve the problems. In this paper recent researches will be reviewed on sources of in-vehicle air pollution and air quality control for human health.

\section{SOURCES OF IN-VEHICLE AIR POLLUTION}

In recent years in-vehicle air pollution caused some civil action cases, reflected the seriousness of the problem that the existing pollution in vehicle is not to be ignored.

The results showed that the source of in-vehicle air pollutants includes four aspects: form auto outer space, untight seal, auto air condition system and vehicle interior.

\section{A. Auto Outer Space}

During driving process, the air in cab exchanges with the air from outer space. In addition to containing nitrogen oxides in air, hydrocarbons and other harmful gas from

\author{
Yue XU \\ State Key Laboratory of Automobile Dynamic Simulation \\ Jilin University, Changchun, Jilin province 130022, China
}

outside, air still contains a lot of sulfur oxides (Wenyi Yang, etc., 2013). During gas exchanges with the outside world and at the same time, a large number of pollutants will enter the vehicle, causing the vehicle air pollution.

\section{B. Tightness}

Inside the vehicle pollutants except from vehicle outer space, also from when the vehicle is going to follow the vehicle exhaust emissions of pollutants and unburned hydrocarbon volatiles. This part contains combustible mixture and combustion products, the most harmful to human beings have oxygen vehiclebon, hydrocarbons, nitrogen oxides and volatile organic lead dust, etc. They are all harmful on human respiratory system, nervous system, etc (Laumbach Robert J, etc, 2010). Living for a long time in the air full of these pollutants room will be serious life-threatening.

\section{Air Conditioning and Ventilation System}

Comparing to the household air-conditioning system, vehicles are normally in state of movement. While working conditions of vehicle air conditioning system is very bad, movement process increases the workload of automotive air conditioning system, but also breeding for pollutants bacteria. However, for the air conditioning ventilation's clean is often easily ignored by people, that will create convenient conditions for the air conditioning system in the accumulation of a large number of bacteria and contaminants, and the spread of mainly pollutants include inhalable particles, microorganism, mold, etc. Even though people seem to enjoy the comfort in-vehicle environment, it may be health threat from the air conditioning system.

\section{Vehicle Interiors}

Modern motors are in pursuit of comfortable and portable, therefore, plastic material, rubber, paint, coatings, adhesives and other composite material are used in automobile interiors. Due to the increasing use of these materials usually contains a large number of organic solvents, additives such as volatile components, which continuously volatilizes into the vehicle, and the main pollutants include benzene, toluene, xylene, formaldehyde, 
vehiclebon dioxide, ammonia and so on. In summer, more amount of volatile organic matters precipitate out with higher temperature; in winter due to low temperature, air flow is slow, the greenhouse gas content increases in vehicle. According to the relevant studies that people would get cancer if he/she contacts with these substances for long time.

\section{AIR POLLUTANTS PURIFICATION MEASURES WITHIN VEHICLES}

The governance of in-vehicle air quality has more than 80 years of history. Purification of in-vehicle air pollution governance can be divided into four stages: heating ventilation and air-conditioning, pollution particles adsorption filtration and disinfection, disinfection sterilization phase and light purification phase.

\section{A. Heating Ventilation and Air-conditioning (HVAC)}

Auto initial design has simple structure, long time using in winter will be frozen hands and feet, in the 1930's thought and with electric vehicle heat fresh air blower marked the first heating device was born in America. The device to provide fresh air into the vehicle in summer appeared until 1940 (Luxiu Liu., 2005). Automobile air conditioning after decades of development changes gradually increase a lot of functions, but the most fundamental or not out of the full design concept to provide for people hot and cold needs, mainly based on refrigeration, heating, defrosting and defogging, air filtration and temperature control for the main function.

\section{B. Contamination Particles Adsorption Filtration Stage}

Activated vehiclebon in the $70 \mathrm{~s}$ and $80 \mathrm{~s}$ of the 20th century in our country was applied to the air pollutant particle adsorption filtration purification field (Fangfang Shi, Limin Li, et al, 2014). Activated vehiclebon can effectively eliminate smoke, and by adopting the method of physical adsorption eliminate harmful material in air. However, physical adsorption of activated vehiclebon only filters out suspended particles, bacteria and microbes in the air, but can't decompose harmful gases, and be easy to saturation. At the same time, the device of used alone activity vehiclebon purifier is more large, it is not used to purify automobile pollution. Through technology improvement, although the purification of the active vehiclebon improved, because of its purification mechanism combined with other techniques used for air purification, therefore most activated vehiclebon for air purification used in the preliminary stage.

\section{Disinfection Sterilization Phase}

Ultraviolet radiation, ozone will produce certain harm to human body, therefore they're only used under the environment of unmanned operation. The two methods of purification are better to improve purification effect on the total number of bacteria, but will not be able to eliminate the air harmful substances, and ozone stimulus is bigger, which is easy to make rubber aging of the metal and speed up the metal corrosion (Haiquan Jia, et al., 2011). Anion generator is introduced from abroad in 1960's, a certain amount of negative ions in the air make a person feel more comfortable, negative ion purification is by means of condensation and absorption effect, make the air anion adhesion in solid or liquid micro pollutants on grain, settling down to form large ions, to reduce air pollution concentration. But negative ions purify only within a certain period of time and it can only fresh air, inhibit bacteria, can not decompose harmful gas. The plasma purification at the same time will produce certain by-product content.

Such as activated vehiclebon, plasma, negative ions, ozone purification technology has been applied to the automobile air conditioning system in different degrees, but because of their respective limitations they are not used to a wide range of application in the vehicle to air pollution control.

\section{Light Purification Phase}

FUJISHIMA invented nanometer light purification technology in 1972, with the radiation of nanometer TiO2, surface water experiences oxidation reduction reaction continually (Jihong Yu, 2010). Oxygen, water vapor and air pollutants molecular adsorption on the catalyst surface in advance is necessary for light purification reaction. When UV irradiation happens, which wavelength is less than 387.5 $\mathrm{nm}$ flash out, electron hole, oxygen in the air and water will happen oxidation reaction, it will produce hydrogen and oxygen free radicals. Hydrogen and oxygen free radicals and the air molecular contamination will be oxidated. Oxygen is consumed, and the pollutants in the air will be broken into harmless vehiclebon dioxide and water.

At present our country also appears the vehicle light catalytic purification materials and cleaner, but the research is still in the start of this kind of technology. About the photocatalytic activities and other measures of purification, the effect and test has not been unified industry technical standards and national standards.

\section{COMMONLY MEASURES TO SOLVE THE VEHICLE POLLUTION}

Usually inside and outside space of vehicle for air exchange include following two ways: One is to open the window and outside air flows into vehicle, the other is that the automotive air conditioning system will exchange the air inside and outside (Chao Ma, 2011). The above two methods just exchange the air in the vehicle and out space by physical process, and are not from the essence of auto purifying air environment.

\section{CONCLUSIONS}

A comfortable and healthy in-vehicle air environment is favorable to occupants. More and more people focus on in-vehicle air quality. However, health problems associated with in-vehicle air quality appear more frequently. A given symptom usually has different causes, while a given pollutant may result in many different symptoms. The biological effects of different pollutants may differ by orders of magnitude. Moreover, the composition of in-vehicle pollutants is quite complex and the concentrations are greatly different. The chemical reactions may occur among in-vehicle pollutants, which can produce more irritating 
secondary pollutants which even cannot be measured for moment. It is not clear that the effect mechanism of these pollutants to human body with exposure under low concentrations and short time levels. It is also uncertain that the impact of exposure amount and exposure time on human health. Only if these problems are resolved can in-vehicle air environment be controlled accurately and reasonably.

\section{REFERENCES}

[1] Peng Liang, Xiaohong Chen, Gaolin Lin. Detection and Controlling strategy for Air pollutant in cabin of Vehicles. [J]. Automobile Parts, 2012, (8):55-57

[2] Wenyi Yang, Jie Li, Lili Zhu, Zifa Wang. Contrast in source of air pollutant emission listing. [J]. Research of Environmental Sciences, 2013, (7):703-711

[3] Laumbach Robert J, Kipen Howard M. Acute effects of motor vehicle traffic-related air pollution exposures on measures of oxidative stress in human airways. [J]. New York Academy of Annais,2010,Vol,1203:107-12
[4] Luxiu Liu. Foreign automotive air conditioning for several development present situation. [J]. Automobile \& Parts Technology, 2005, (9):26-31.

[5] Fangfang Shi, Limin Li, Chuan Yu, Lin Zhang, Jia Song, Renyuan Yan. Indoor air purification technology and product review. [J].Journal of Refrigeration, 2014, (5):14-18

[6] Haiquan Jia, Xin Pan, Zongxing Zhang, Jinming Zhang, Huoju Xu, Jiancheng Qi. High intensity ultraviolet air purification device of air bacteria killing efficiency in experimental study. [J], Chinese Journal of Nosocomiology, 2011, (10):2051-2053

[7] Jihong Yu. Nanometer photocatalysis technology application in indoor air purification. [J]. Environmental Protection and Circular Economy, 2010, (5):60-62

[8] Chao Ma. The present situation and the development tendency of the indoor air pollution purification technology. [J]. Environmental Engineering, 2011, (S1):168-170

[9] Yaosheng He, Air pollutants and its components and cardiopulmonary disease, coronary heart disease death in epidemiological studies, [M], 2014

[10] George Odhiambo, A.M.Kinyua, C.K.Gatebe, J.Awange, Motor Vehicles Air Pollution in Nairobi, Kenya.[J]. Research Journal of Environmental and Earth Sciences, 2010, Vol.2 (4):178-187 